\title{
Dynamics of ion-regulated photoinduced electron transfer in BODIPY-BAPTA conjugates
}

\author{
Pinar Batat, ${ }^{a, b}$ Guillaume Vives, ${ }^{a}$ Robin Bofinger, ${ }^{a}$ Ren-Wei Chang,,${ }^{a, c}$ Brice Kauffmann, ${ }^{d}$ Reiko Oda, ${ }^{c}$ \\ Gediminas Jonusauskas ${ }^{*} b$ and Nathan D. McClenaghan*a
}

\begin{abstract}
Efficient $\mathrm{Ca}^{2+}$ switched fluorescent sensors, where fluorescence output is governed by a light activated ion gated electron transfer pathway, can be obtained on combining BODIPY chromophores with a readily oxidized biocompatible and selective BAPTA receptor. Herein we report the synthesis and studies of two such conjugates, which vary in the nature of the spacer separating the two electroactive components, namely none (1) or phenyl (2). Single crystal X ray crystallography and molecular modelling structures and calculations give information on molecular and electronic structure, while steady state fluorescence experiments show high $\mathrm{Ca}^{2+}$ induced fluorescence enhancement factors of 122 and 23 and $K_{\mathrm{d}}$ values of $0.50 \mu \mathrm{M}$ and $0.13 \mu \mathrm{M}$ for $\mathbf{1}$ and $\mathbf{2}$, respectively. Notably, studies of the ultrafast photoinduced processes (through transient absorption spectroscopy) give access to electron transfer dynamics in pseudo physiological media as well as in a polar non protic solvent and information about the fate of the excited molecules in the presence and absence of calcium. In water, electron transfer rates as high as $3.3 \times 10^{12} \mathrm{~s}^{-1}$ and $8.3 \times 10^{11} \mathrm{~s}^{-1}$ are measured for the ion free, directly connected conjugate and the variant incorporating a phenyl spacer, respectively. This electron transfer pathway is efficiently blocked by the presence of an ion, restoring fluorescence.
\end{abstract}

\section{Introduction}

The design and understanding of chemosensors for monitoring biologically important ions in solution is currently of great importance, allowing real time environmental monitoring and tracking biological events using fluorescence techniques, harnes sing ever improving microscopy and detection systems. ${ }^{1}$ Among the wide variety of chemical messengers used by cells for

a Univ. Bordeaux/CNRS, ISM, 351 cours de la Libération, 33405 Talence Cedex, France.E-mail: n.mc-clenaghan@ism.u-bordeaux1.fr; Fax: +33 (0)540006158; Tel: +33 (0)540003321

${ }^{b}$ Univ. Bordeaux/CNRS, LOMA, 351 cours de la Libération, 33405 Talence cedex, France.E-mail: g.jonusauskas@loma.u-bordeauxl.fr; Tel: +33 (0) 540006198

cInstitute of Chemistry \& Biology of Membranes \& Nanoobjects (UMR5248 CBMN) CNRS Universite Bordeaux Institut Polytechnique Bordeaux, Institut Européen de Chimie et Biologie, 2 rue Robert Escarpit, 33607 Pessac, France.

E-mail: r.oda@iecb.u-bordeaux.fr; Tel: +33 (0)540002229

${ }^{d}$ Univ. Bordeaux/CNRS, IECB, 2 Rue Robert Escarpit, Pessac 33607, France.E-mail: b.kauffmann@iecb.u-bordeaux.fr; Tel: $+33(0) 540003054$ signaling, ionized calcium $\left(\mathrm{Ca}^{2+}\right)$ is perhaps the single most important information carrier. ${ }^{2}$ Integrating specific high affinity receptors with a fluorophore, such that ion recognition results in a modified fluorescence output, can be arranged by several different designs. ${ }^{3}$ Among the most successful fluorescent chemo sensors that show a spectral response upon binding $\mathrm{Ca}^{2+}$ are derivatives of the $\mathrm{Ca}^{2+}$ chelators EGTA (ethylene glycol $\operatorname{bis}\left(\beta\right.$ aminoethyl ether) $N, N, N^{\prime}, N^{\prime}$ tetraacetic acid), APTRA (o aminophenol $N, N, O$ triacetic acid $)^{4}$ and BAPTA $[1,2$ bis (o aminophenoxy) ethane $N, N, N^{\prime}, N^{\prime}$ tetraacetic acid]..$^{5}$ High affinity $\mathrm{Ca}^{2+}$ chelators, such as EGTA, had been studied for many years, but the $\mathrm{Ca}^{2+}$ affinity of these molecules is very sen sitive to changes of $\mathrm{pH}$ in the physiological range (6.5 7.5). Adding two aromatic rings to the backbone of EGTA to create BAPTA overcame this problem, while maintaining the high $\mathrm{Ca}^{2+}$ and low $\mathrm{Mg}^{2+}$ affinity of EGTA. Thus BAPTA was chosen for its high calcium affinity in physiological medium to be the calcium ligand in the current fluorescent probes.

While the protoype examples (including Fura 2$)^{6}$ were based on an ion induced fluorescence spectral shift using a Photo induced Charge Transfer (PCT) chromophore, some highly perfor mant examples were based on a Photoinduced Electron Transfer (PET) process. In this case the thermodynamically favourable electron transfer from the anilinic donor, which forms part of the BAPTA receptor, to the excited fluorophore serves to quench the fluorescence. On binding an ion this PET process becomes unfavourable due to the changing potential of oxidation of the 


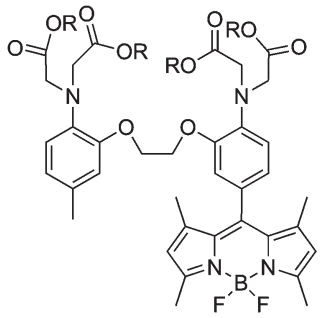

1: $\mathrm{R}=\mathrm{H}$

1a: $R=E t$

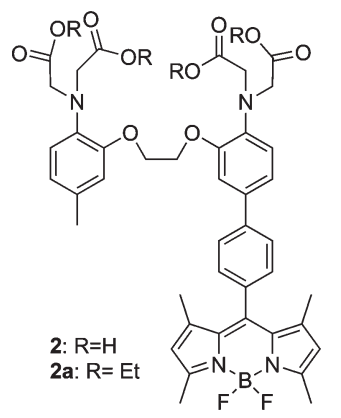

Scheme 1 Structural formulae of BODIPY BAPTA conjugates 1, 1a, 2 and $\mathbf{2 a}$.

aniline unit, and so fluorescence is restored. Examples with varying levels of success have been reported on this principle, based on one photon ${ }^{7}$ and two photon absorption. ${ }^{8}$ Equally, simultaneous reporters for both protons and $\mathrm{Ca}^{2+}$ are known. ${ }^{9}$

Concerning the choice of fluorophore, in recent years, much attention has been focused on the synthesis of 4,4 difluoro 4 bora 3a,4a diaza $s$ indacene (boron dipyrromethene or BODIPY) based fluorescent probes and their application as selective and sensitive chemosensors. ${ }^{10}$ BODIPY is a well known fluorophore characterized by useful properties, such as excellent thermal and photochemical stability, high fluorescence quantum yield and substituent tunable emission in the visible/ NIR, negligible/low unwanted triplet state formation in the absence of heavy metals, intense absorption, high solubility in many solvents, and chemical robustness. ${ }^{11}$ Moreover, boron dipyrromethene dyes can be excited with visible light, have narrow emission bandwidths with high peak intensities, and are open to structural modification. In this regard, modification is not limited to the organic part as the Lewis acid boron centre, being susceptible to nucleophilic attack from aryl Grignards, acetylide anions or alkoxides, ${ }^{12}$ can also be substituted and thus serve as a means to fix the dyes on a substrate. ${ }^{13}$

BODIPY analogues, and related systems, ${ }^{14}$ with different receptors have recently been described as fluorescent probes for $\mathrm{H}^{+},{ }^{11,15} \mathrm{Na}^{+},{ }^{16} \mathrm{~K}^{+},{ }^{17} \mathrm{Ca}^{2+},{ }^{18} \mathrm{Ag}^{+},{ }^{19} \mathrm{Zn}^{2+},{ }^{20}$ or $\mathrm{Hg}^{2+} \cdot{ }^{21}$ Equally during this work a few BAPTA BODIPY switching derivatives have been reported with high fluorescence enhancements, which have been applied in cellular imaging and used to selectively label proteins, such as the SNAP tag fusion proteins (DNA repairing proteins) in living cells. ${ }^{22}$ However, for all these systems where photoinduced electron transfer can be inferred on the basis of redox potentials and excited state energies, few (or no) studies have been carried out to the best of our knowledge to quantify and characterize the electron transfer process using time resolved spectroscopies.

In this article we report the synthesis and characterization, both structural and photophysical, of two new fluorescent calcium probes (see Scheme 1) based on a BAPTA $\mathrm{Ca}^{2+}$ ligand linked to a BODIPY fluorescent reporter group, either directly or connected via a phenylene spacer. Ion regulated properties of these conjugates were studied using fluorescence emission and transient absorption spectroscopy, while the $\mathrm{Ca}^{2+}$ binding was investigated by fluorometric and spectrophotometric titrations.

\section{Experimental section}

$\mathrm{BF}_{2}$ dipyrromethene conjugates were synthesized as outlined in the results and discussion section, and detailed in the ESI.t Electronic absorption spectra were recorded on a UV vis NIR Varian Cary 5000. Fluorescence emission and excitation spectra of optically dilute solutions were recorded on a Horiba Jobin Yvon Fluorolog 3 with TCSPC mode, equipped with UV vis NIR detector R2658P and NIR detector H10330 45. Degassed samples were studied in blowtorch sealed cells, having been thoroughly degassed by multiple freeze pump thaw cycles. The picosecond transient absorption/time resolved fluorescence set up was built as follows. A frequency tripled $\mathrm{Nd}$ :YAG amplified laser system (30 ps, 30 mJ @1064 nm, 20 Hz, Ekspla model PL 2143) output was used to pump an optical parametric generator (Ekspla model PG 401) producing tunable excitation pulses in the range $4102300 \mathrm{~nm}$. The residual fundamental laser radiation was focused in a high pressure Xe filled break down cell where a white light pulse for sample probing was pro duced. All light signals were analyzed by a spectrograph (Princeton Instruments Acton model SP2300) coupled with a high dynamic range streak camera (Hamamatsu C7700). Accumulated sequences of pulses (sample emission, probe with and without excitation) were recorded and treated by HPDTA (Hamamatsu) software to produce two dimensional maps (wave length vs. delay) of transient absorption intensity in the range $300800 \mathrm{~nm}$. Typical measurement error was better than $10^{-3}$ O.D. Samples were equally studied on the sub picosecond timescale. A Ti:Sapphire laser system emitting pulses of $0.6 \mathrm{~mJ}$ and $30 \mathrm{fs}$ at $800 \mathrm{~nm}$ and $1 \mathrm{kHz}$ pulse repetition rate (Femtopower Compact Pro) with optical parametric generator (Light Conver sion Topas C) and frequency mixers was used to excite samples at the maximum of the steady state absorption band. White light continuum (360 nm $1000 \mathrm{~nm}$ ) pulses generated in a $5 \mathrm{~mm} \mathrm{D}_{2} \mathrm{O}$ cell were used as a probe. The variable delay time between exci tation and probe pulses was obtained using a delay line with $0.1 \mu \mathrm{m}$ resolution. The solutions were placed in a $1 \mathrm{~mm}$ circula ting cell. White light signal and reference spectra were recorded using a two channel fiber spectrometer (Avantes Avaspec 2048 2). A home written acquisition and experiment control program in LabView made it possible to record transient spectra with an average error less than $10^{-3}$ of optical density for all wavelengths. The temporal resolution of the set up was better than $50 \mathrm{fs}$. A temporal chirp of probe pulse was corrected by a computer program with respect to a Lawrencian fit of a Kerr signal generated in a $0.2 \mathrm{~mm}$ glass plate used in place of a sample. Air equilibrated solutions were employed for ultrafast studies.

\section{Results and discussion}

\section{Synthesis of BODIPY-BAPTA conjugates}

The synthesis of BODIPY BAPTA conjugates was performed according to Scheme 2, see ESI $\$$ for detailed synthetic pro cedures. Briefly, BODIPY BAPTA 1 was synthesized in three steps starting from methyl BAPTA 3. ${ }^{6}$ Molecule $\mathbf{3}$ was formy lated using a Vilsmeier Haack procedure to yield 4 in a $74 \%$ yield. ${ }^{6}$ The BODIPY moiety was then obtained by a three step one pot reaction. ${ }^{23}$ BAPTA aldehyde 4 was first reacted 

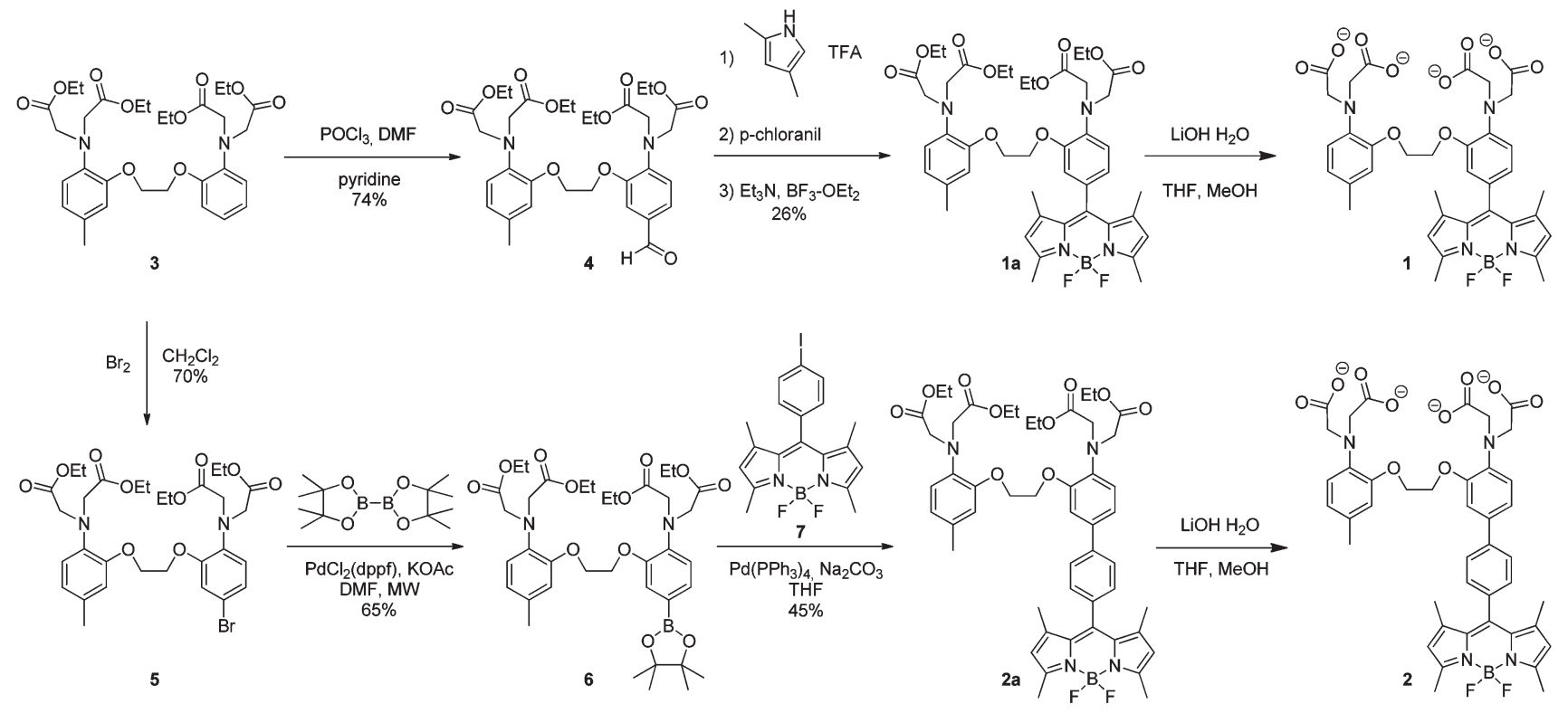

Scheme 2 The synthesis of BODIPY BAPTA conjugates $\mathbf{1}$ and $\mathbf{2}$.

with 2,4 dimethyl pyrrole to afford a dipyrromethane intermedi ate, which was oxidized by $p$ chloranil to a dipyrromethene intermediate, which then reacted with $\mathrm{BF}_{3}$ to yield $\mathbf{1 a}$ in a $26 \%$ overall yield. BODIPY Ph BAPTA (2) was synthesized by a modular approach using a Suzuki coupling between BAPTA boronic ester 6 and 4 iodophenyl BODIPY 7. ${ }^{24}$ Indeed, this approach was considered a versatile method to potentially intro duce different functional units on the BAPTA unit via a mild $\mathrm{C} \mathrm{C}$ bond forming reaction. 3 was brominated with bromine in dichloromethane at room temperature to yield $5^{5}$ The bromine of 5 was then converted into a boronic ester by the Miyaura methodology. ${ }^{25}$ Compound $\mathbf{5}$ was heated in DMF under micro wave irradiation with $\left[\mathrm{PdCl}_{2}(\mathrm{dppf})\right], \mathrm{dppf}=1,1^{\prime}$ bis(diphenyl phosphino)ferrocene, and bis(pinacolato)diboron to give 6 in a $65 \%$ yield. A final Suzuki coupling with 4 iodophenyl BODIPY 7 afforded $\mathbf{2 a}$ in a $45 \%$ yield.

Esters or activated esters are employed in biological systems to cross cell membranes to be subsequently actived in situ by esterases unmasking the receptor, here studies were carried out on both. ${ }^{26-28}$ The synthesized BAPTA esters 1a and 2a were transformed into the corresponding lithium salts $\mathbf{1}$ and $\mathbf{2}$ by sapo nification under mild conditions with lithium hydroxide in a mixture of THF and methanol. Subsequent rinsing of the residue with ethyl acetate, acid reprecipitation from water and lyophiliza tion gave the product. This clean hydrolysis procedure (as deter mined by reverse phase thin layer chromatographic analysis) allowed us to use the carboxylate derivatives without further purification in the calcium complexation studies.

\section{Molecular conjugate structure: single crystal X-ray diffraction studies}

One structural factor that is conducive with high fluorescence from BODIPYs which are meso substituted with phenyl groups is that the phenyl ring plane presents an angle approaching orthogonality to the BODIPY plane. ${ }^{29}$ This can be achieved due to steric hindrance which may be anticipated to be induced partly by the methyl groups in $\mathbf{1}$ and $\mathbf{2}$. In some representative examples, incorporation of a para bromophenyl group in the meso position resulted in an angle of $78.9^{\circ}$ between planes; a 4 dimethylamino group gave $87.6^{\circ}$, while a perfluorophenyl group gave $90.0^{\circ} .{ }^{30} \mathrm{~A}$ survey of 31 different structures in the CCDC with different substituents shows that the average angle between the phenyl and the BODIPY is $81.26^{\circ}$, the least twisted

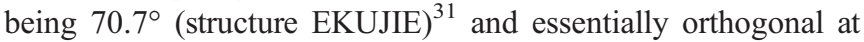
$89.85^{\circ}$ (structure JIZLUA). ${ }^{32}$ Concerning planarity, the average deviation from the ideal is $0.054 \AA$ with a maximal deviation of $0.219 \AA$.

The single crystal $X$ ray structural determination of $\mathbf{1 a}$ and $\mathbf{2 a}$ confirms an approach to the anticipated orthogonal arrangement of the phenyl and dipyrromethene fragments (Fig. 1), which is imposed by the substituents.

The dihedral angles between the BODIPY and the phenyl fragments for $\mathbf{1 a}$ and $\mathbf{2 a}$, respectively, are $87.2^{\circ}$ and $85.8^{\circ}$, while the phenyl rings in the biphenyl fragment of $\mathbf{2 a}$ are slightly tilted with a dihedral angle of $28.0^{\circ}$. The diazaindacene fragments are essentially planar, the maximum deviation from the least squares mean plane of the 12 atoms of the indacene groups is $\pm 0.087 \AA$ for $\mathbf{1 a}$ and $\pm 0.080 \AA$ for $\mathbf{2 a}$. The bond distances for the indacene fragments are in good agreement with related systems reported in the literature, ${ }^{33}$ with an average $\mathrm{B} \mathrm{N}$ bond length of $1.54 \AA$ and average B F bond length of $1.39 \AA$.

\section{Quantum chemical calculations}

Quantum chemical calculations were performed using MOPAC2007 software (PM6 Hamiltonian, COSMO solvation model for acetonitrile). ${ }^{34}$ One aniline of BAPTA connected with BODIPY is used in order to simplify the calculations. Molecular orbitals involved in electron transfer are depicted in Fig. 2. The HOMO - 1 and LUMO are located on the BODIPY fragment of the compounds and represent the molecular orbitals which are 

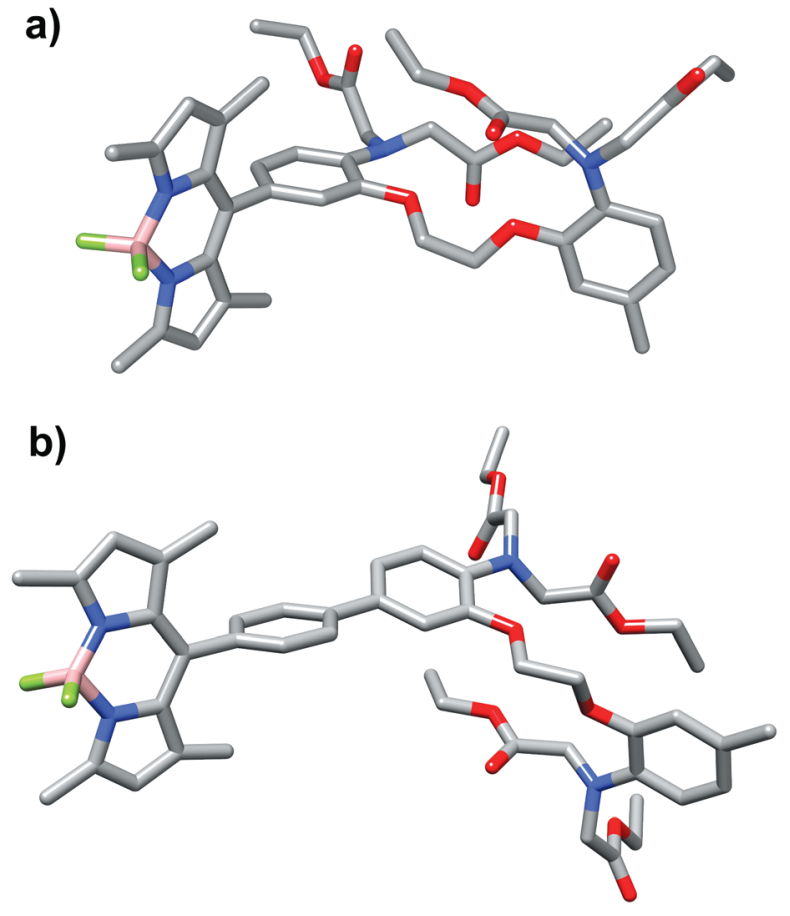

Fig. 1 Single crystal X ray diffraction structures of $\mathbf{1 a}$ (a) and $\mathbf{2 a}(\mathrm{b})$.
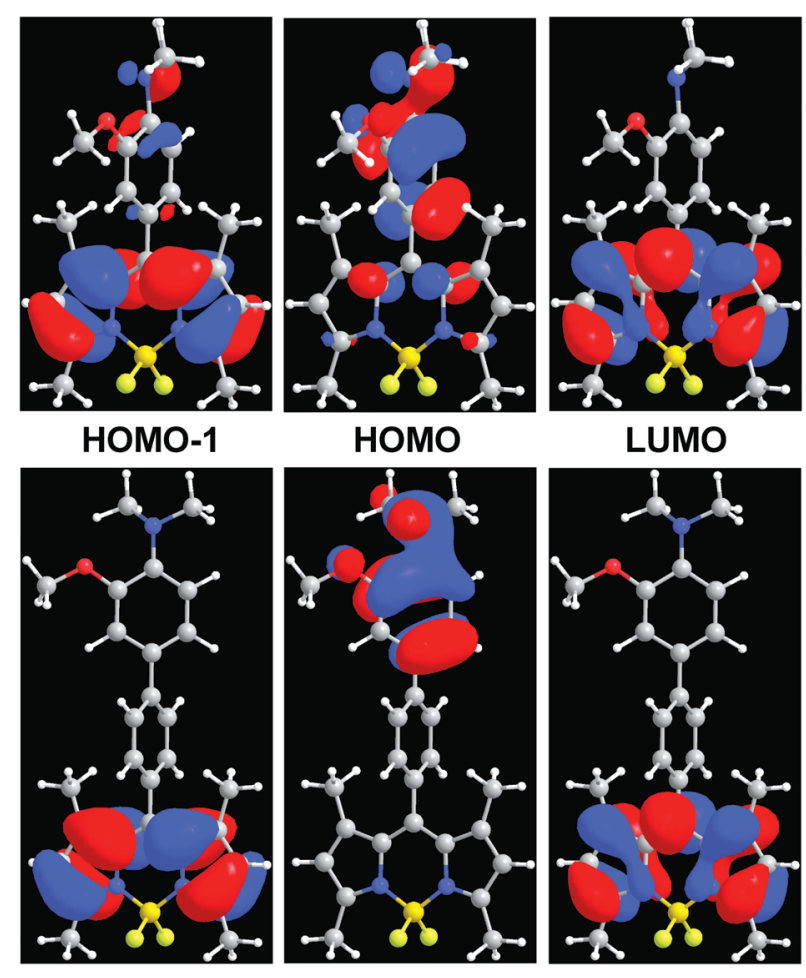

Fig. 2 The HOMO 1, HOMO and LUMO orbitals on models for molecule 1 (top) and 2 (bottom).

involved the lowest gap optically active transition. The aniline of BAPTA is almost perpendicular with respect to the BODIPY part of the molecule representing $\mathbf{1}$, due to steric hindrance intro duced by the $\alpha$ methyls. According to calculations the angle
Table 1 Spectroscopic properties of BODIPY BAPTA 1 and 2 (under pseudo physiological conditions) and their ester analogues $\mathbf{1 a}$ and $\mathbf{2 a}$ (in THF)

\begin{tabular}{|c|c|c|c|c|c|c|}
\hline & $\begin{array}{l}\lambda_{\max } \\
(\mathrm{nm})\end{array}$ & $\begin{array}{l}\varepsilon \\
\left(\mathrm{M}^{-1} \mathrm{~cm}^{-1}\right)\end{array}$ & $\lambda_{\mathrm{em}}$ & $\Phi_{\mathrm{em}}$ & $\mathrm{p} K_{\mathrm{d}}$ & $F_{\text {max }} / F_{\text {min }}$ \\
\hline $1 \mathrm{a}$ & 501 & 79500 & 514 & 0.01 & & N/A \\
\hline $2 a$ & 501 & 82800 & 512 & 0.04 & & N/A \\
\hline 1 & 498 & $a$ & 508 & $\begin{array}{l}3 \times 10^{-4 b} \\
(0.001)^{c}\end{array}$ & & N/A \\
\hline 2 & 497 & $a$ & 507 & $\begin{array}{l}4 \times 10^{-3 b} \\
(0.005)^{c}\end{array}$ & & N/A \\
\hline 1. $\mathrm{Ca}^{2+}$ & 498 & $a$ & 508 & 0.04 & $6.3^{d}$ & 122 \\
\hline 2. $\mathrm{Ca}^{2+}$ & 497 & $a$ & 507 & 0.09 & $6.9^{d}$ & 23 \\
\hline
\end{tabular}

${ }^{a}$ Uncertainty of hydration state prohibits accurate determination. ${ }^{b}$ Determined from switched "on" $\Phi_{\mathrm{em}} /\left(F_{\max } / F_{\min }\right) .{ }^{c}$ Directly measured.

${ }^{d}$ Determined from fluorescence titrations. N/A = Non applicable.

between them is found to be $88^{\circ}$, thus being very similar to that obtained through single crystal $\mathrm{X}$ ray analysis. While approaches to orthogonality are anticipated to decouple the adjacent $\pi$ systems, it is clear there is some electronic communication between them, notably in the HOMO level (Fig. 2, top). This may be anticipated to give rise to some spectral modifications in certain solvents, vide infra. In the case of the model for $\mathbf{2}$, the electronic systems of the two halves of the compound are fully deconjugated, as observed for the HOMO -1 , HOMO and LUMO levels.

Thus, the HOMO located on BAPTA is not affected by the transition LUMO $\leftarrow$ HOMO -1 and participates as the electron donating orbital in the charge separation reaction. The twist angle between BODIPY and the phenyl spacer is estimated at $89^{\circ}$, while that between the phenyl and aniline unit is a lot less pronounced at $51^{\circ}$. In summary, while similar donor and fluoro phore/acceptor components are present in both cases, a more intimate coupling is observed in the case of $\mathbf{1}$, which may influence the rate of charge separation, efficiency of fluorescence enhancement, and emission, whilst a more straightforward case may be anticipated in the case of $\mathbf{2}$, which conforms more readily to the successful "receptor spacer fluorophore" format due to the intermediate phenyl ring.

\section{Electronic absorption and fluorescence spectroscopy}

The synthesized BODIPY BAPTA ester derivatives 1a and 2a were first investigated in THF solution by steady state electronic absorption and emission spectroscopies (see Table 1).

Compound 1a and 2a exhibit an absorption maximum at $501 \mathrm{~nm}$ with similarly high molar extinction coefficients and a band shape characteristic of BODIPY derivatives. ${ }^{10 b}$ The BODIPY based emission maxima (see Fig. 3) were observed at 514 (1a) and $512 \mathrm{~nm}$ (2a), showing small Stokes shifts $(\Delta \omega=$ $500 \mathrm{~cm}^{-1}$ and $430 \mathrm{~cm}^{-1}$ for $1 \mathbf{a}$ and $\mathbf{2 a}$, respectively), which are similarly low for 1 and 2 in water at $\Delta \omega=400 \mathrm{~cm}^{-1}$ and $440 \mathrm{~cm}^{-1}$, respectively. Compound 1a has a low fluorescence quantum yield (0.01), which increases by a factor of about four for $\mathbf{2 a}$.

The rather low quantum yield values for 1a and 2a compared to native BODIPY fluorophores may be explained by an efficient 


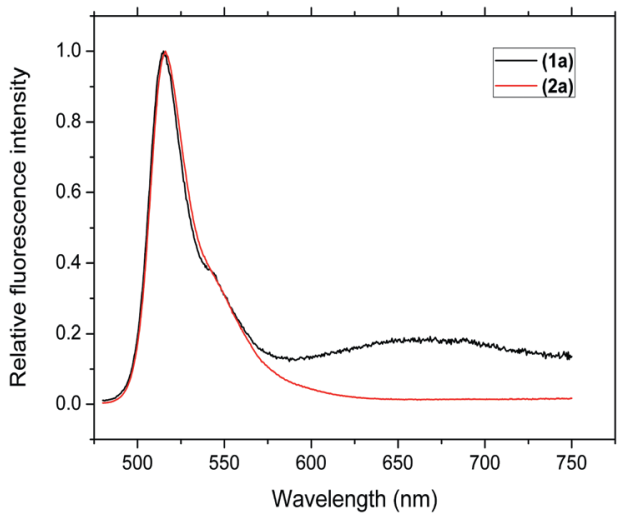

Fig. 3 Normalised steady state emission spectra of ethyl ester deriva tives 1a and 2a in $\operatorname{THF}\left(\lambda_{\mathrm{ex}}=470 \mathrm{~nm}\right)$.

quenching by a photoinduced electron transfer or charge transfer process, analogous to the process in a $N, N$ dimethylanilino BODIPY derivative described in the literature (resembling the case of 1a), in this case from BAPTA to the excited BODIPY unit. $^{35}$

We note in passing that a dual emission was observed from the cited $N, N$ dimethylanilino BODIPY derivative in certain sol vents, including THF where the charge transfer (ICT) emission intensity was around 47 times that of the locally excited emis sion. However, in the current case the relative contribution of the charge transfer emission ( $\tau=950 \mathrm{ps})$ to the total emission could be estimated to be circa 100 times less. This second emission was seen to disappear in more polar acetonitrile and would not be anticipated in aqueous mixtures, which will be the primary focus of the following sections. In the case of 2a, only weak BODIPY emission from the locally excited state was observed in THF.

\section{Calcium complexation studies}

The effective dissociation constants $K_{\mathrm{d}}$ of the calcium complexes (i.e. $1 / \beta)$ of $\mathbf{1}$ and $\mathbf{2}$ were determined in buffered aqueous solu tion by spectrophotometric (see ESIł) and fluorometric titrations as a function of $\mathrm{Ca}^{2+}$ concentration (see Fig. 4 and 5 for $\mathbf{1}$ and $\mathbf{2}$, respectively). The ionic strength of the pseudo intracellular environment was assured at $0.1 \mathrm{M} \mathrm{KCl}$ and $\mathrm{pH}=7.20$ (using $0.03 \mathrm{M}$ MOPS (3 $[N$ morpholino]propanesulfonic acid buffer) while the free $\mathrm{Ca}^{2+}$ concentrations were adjusted by use of EGTA as described by Tsien.,

For both $\mathbf{1}$ and 2, the visible spectral region of the electronic absorption spectra was minimally affected on complexing calcium (see ESI:). However, significant changes in the UV region were attributed to calcium induced perturbations of $O$ alkoxy anilino moiety on complexation by the BAPTA recep tor. These spectral variations allowed ground state dissociation constant $\left(K_{\mathrm{d}}\right)$ determination at $0.26 \mu \mathrm{M}$ and $0.11 \mu \mathrm{M}$ for $\mathbf{1}$ and 2, respectively (see ESI:).

Nonlinear fitting of eqn (1) to the steady state fluorescence data $F$, recorded as a function of $\left[\mathrm{Ca}^{2+}\right]$, yields values of $K_{\mathrm{d}}$, the fluorescence signals $F_{\min }$ and $F_{\max }$ at minimal and maximal $\left[\mathrm{Ca}^{2+}\right]$, respectively (corresponding to the free and $\mathrm{Ca}^{2+}$ bound

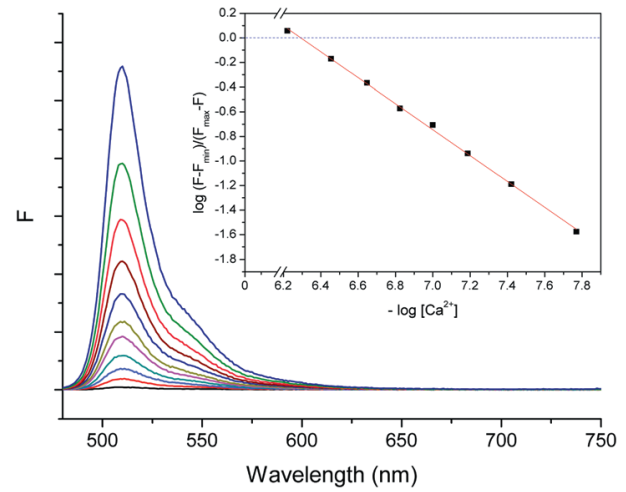

Fig. 4 Emission spectra of $\mathbf{1}$ as a function of $\mathrm{Ca}^{2+}$ concentration $\left(\lambda_{\mathrm{ex}}=\right.$ $475 \mathrm{~nm}$ ) in buffered aqueous solution. Inset: Hill plot for ion binding on monitoring at $515 \mathrm{~nm}$.

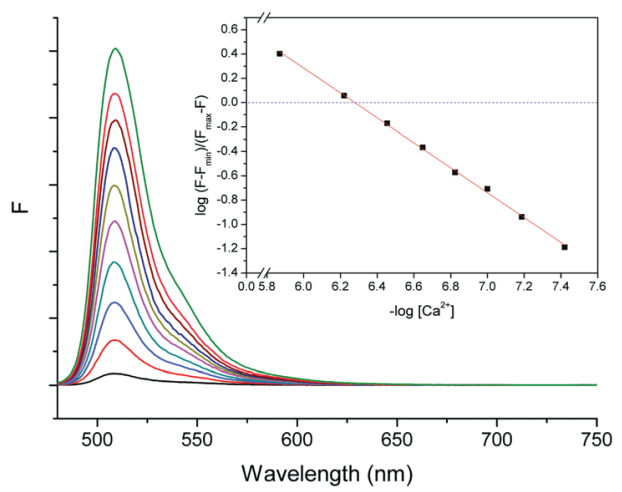

Fig. 5 Emission spectra of 2 as a function of $\mathrm{Ca}^{2+}$ concentration $\left(\lambda_{\mathrm{ex}}=\right.$ $475 \mathrm{~nm}$ ) in buffered aqueous solution. Inset: Hill plot for ion binding on monitoring at $509 \mathrm{~nm}$.

forms of the probe, respectively). Eqn (1) assumes that the absor bance of the sample is small $(<0.1)$ and that $\mathrm{Ca}^{2+}$ complex for mation in the excited state is negligible.

$$
\left[\mathrm{Ca}^{2+}\right]=K_{\mathrm{d}} \times \frac{\left(F-F_{\min }\right)}{\left(F_{\max }-F\right)}
$$

In the absence of $\mathrm{Ca}^{2+}$, very weak fluorescence was observed for both $\mathbf{1}$ and $\mathbf{2}$, however the quantum yield for $\mathbf{2}$ $\left(\Phi_{\mathrm{em}}=5 \times 10^{-3}\right)$ was around 10 times that of $\mathbf{1}$. This low emis sion, and hence strong quenching, with respect to the parent fluorophore is consistent with a thermodynamically allowed photo induced electron transfer process. The added donor acceptor distance in the case of $\mathbf{2}$, due to the ancillary phenyl group, and decreased $\pi$ system interaction would be expected to result in a less efficient quenching and hence higher quantum yield.

A large increase of the fluorescence intensity quantum yield was observed upon addition of calcium in both cases, without a shift of the maxima. As the lone electron pair of the amino group of the BAPTA moiety is known to be involved in the binding of $\mathrm{Ca}^{2+}$, thus calcium coordination partially blocks the PET process and yields an increased fluorescence. A fluore scence enhancement factor (FEF) of 122 for $\mathbf{1}$ compared to 23 for $\mathbf{2}$, again shows a more intimate donor acceptor 
interaction. Fluorescence quantum yields of the complexes $\mathbf{1}$. $\mathrm{Ca}^{2+}$ and 2. $\mathrm{Ca}^{2+}$ were established at 0.04 and 0.09 , which in turn, on considering the FEFs, gave values of $3 \times 10^{-4}$ and $4 \times 10^{-3}$ for ion free $\mathbf{1}$ and $\mathbf{2}$, respectively. (Note: direct measurement gave values of $1 \times 10^{-3}$ and $5 \times 10^{-3}$, but with greater uncertainty due to a lower signal to noise ratio).

The data obtained by fluorometric titrations for the indicators $\mathbf{1}$ and $\mathbf{2}$ are summarized in Table 1. The calcium dissociation constants $K_{\mathrm{d}}$ were obtained for these indicators, giving $K_{\mathrm{d}}$ values of $0.53 \mu \mathrm{M}$ and $0.12 \mu \mathrm{M}$ for $\mathbf{1}$ and $\mathbf{2}$, thus showing a similar trend to spectrophotometrically determined values and in a typical range for known BAPTA calcium indicators.

\section{Time-resolved transient absorption studies}

Transient absorption spectroscopy offers a means to follow the evolution of the excited molecular system, particularly as BODIPY triplet absorption spectra have been recently reported ${ }^{36}$ as well as a spectroelectrochemical study of BODIPY radical anion formation ${ }^{37}$ allowing disentanglement of the transfer pathway. Equally, stimulated emission decays give information on fluorescence. Thus, excited 1a in THF exhibits, in addition to ground state bleaching, a positive absorption band at $420 \mathrm{~nm}$ and a negative (stimulated emission) band at $520 \mathrm{~nm}$, which decay completely in concert in 30 ps (see kinetics and deconvolution in ESI $\$$ ), giving way to positive bands at $520 \mathrm{~nm}$ and $570 \mathrm{~nm}$. From longer timescale experiments (with a wider available conti nuum) an additional positive band at $330 \mathrm{~nm}$ is also observed, which like the aforementioned radical signatures, decays in $1 \mathrm{~ns}$, giving rise to a more persistent signature clearly visible at $425 \mathrm{~nm}$ (with no apparent decay in $10 \mathrm{~ns}$ ). On comparison with reference BODIPY spectra, ${ }^{36,37}$ the Franck Condon state rapidly ( $\tau=6 \mathrm{ps}$ ) evolves to the charge separated state, which ultimately slowly (1 ns) gives rise to persistent triplet states ( $\gg 10 \mathrm{~ns}$ ), each with a characteristic transient absorption spectrum (shown in ESI + ). Interestingly, it was previously noted in transition metal BODIPY dyads that, despite favourable PET energetics, the BODIPY triplet was ultimately obtained in acetonitrile. ${ }^{36}$ In the current case a driving force of PET of $\Delta G_{\mathrm{ET}}=c a$. $-0.3 \mathrm{eV}$ can be estimated based on the ground state oxidation of the receptor and the reduction of the excited BODIPY, showing it to be an energetically favourable process and, in the absence of signifi cant spin orbit coupling, more efficient than population of the low lying triplet $(c a .1 .6 \mathrm{eV})$ from the excited BODIPY singlet. $^{36,37}$

On acidifying with perchloric acid the transient absorption spectrum is greatly simplified, where singlet absorption bands at $330 \mathrm{~nm}$ and $425 \mathrm{~nm}$, as well as ground state bleaching and stimulated emission, decay at the same rate $(\tau=4 \mathrm{~ns})$, with no evidence for radical or triplet formation. Similar spectral features would be anticipated on complexing calcium, which would engage the same donor lone pair, albeit to a significantly lesser extent.

Similar behaviour is observed in the transient absorption spectra of excited 2a in THF (see ESI $\$$ ), in terms of sequential singlet population and charge separation, ultimately giving rise to triplets. However, in this case the relative intensities of certain bands are different, which is partly attributed to the orientation
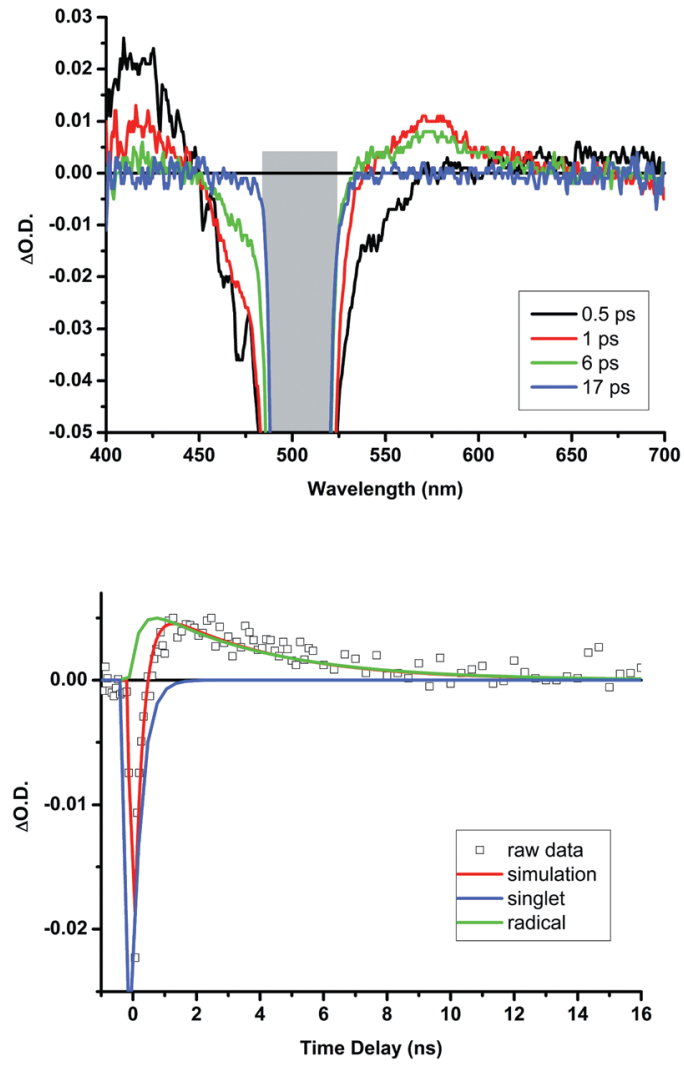

Fig. 6 (Top) Transient absorption spectra of $\mathbf{1}$ in buffered aqueous solution $\left(\lambda_{\mathrm{ex}}=500 \mathrm{~nm}\right.$, grey shading = region of pump scattering $)$ and kinetics at $540 \mathrm{~nm}$ of radical grow in from excited singlet (bottom).

of the central phenyl. Concerning kinetics, the excited singlet absorption band at $425 \mathrm{~nm}$ decays with a time constant of $30 \mathrm{ps}$, which is also seen in the ground state bleaching signal at $470 \mathrm{~nm}$ and in the stimulated emission at $520 \mathrm{~nm}$. The positive band between $550 \mathrm{~nm}$ and $800 \mathrm{~nm}$ can be attributed to the anion radical of BODIPY and the band at $340 \mathrm{~nm}$, which can also be attributed to radicals, potentially receives contributions from both the receptor localized cation and the BODIPY anion. All bands decay in 350 ps giving rise to the triplet state. Adding acid to $\mathbf{2 a}$ in THF gave rise to similar spectra to $\mathbf{1 a} \cdot \mathrm{H}^{+}$, with positive bands at $330 \mathrm{~nm}$ and $420 \mathrm{~nm}$ with a $470 \mathrm{~nm}$ ground state bleaching and a $510 \mathrm{~nm}$ gain band. All bands decay with a common time constant of 2.5 ns. In summary, globally similar processes are observed for $\mathbf{1 a}$ and $\mathbf{2 a}$ in THF, but radical for mation is 5 times slower for $\mathbf{2 a}$ due partly to a greater donor acceptor distance and radicals evolve more rapidly to the triplet state than 1a. Protonation blocks the electron transfer in both cases, giving rise to intense nanosecond fluorescence.

Transient absorption spectra for hydrolyzed molecules $\mathbf{1}$ and $\mathbf{2}$ in buffered water are given in Fig. 6 and 7 and in the ESI. On extremely short timescales there is a short wide positive band seen on both spectra, which is attributed to non linear pheno mena in the solvent. By fitting the gain band at $530 \mathrm{~nm}$, the relaxation time of singlets is determined to be 300 fs for $\mathbf{1}$. While the gain band disappears, new characteristic absorption bands appear at $420 \mathrm{~nm}$ and $570 \mathrm{~nm}$, which are attributed to anion radical absorption bands of BODIPY. 

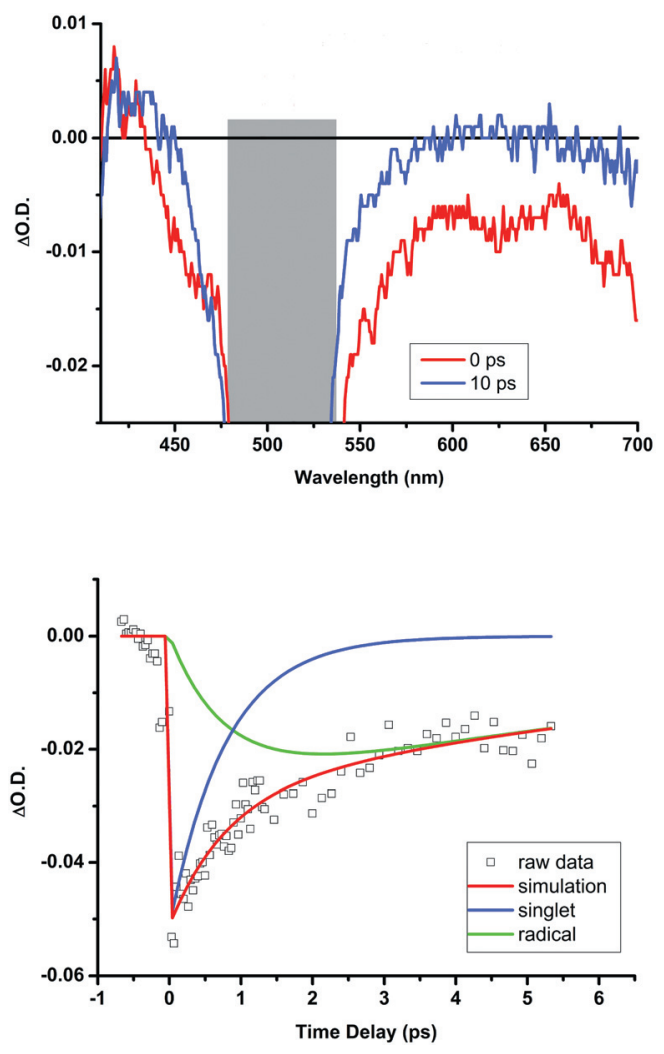

Fig. 7 (Top) Transient absorption spectra of 2 in buffered aqueous solution $\left(\lambda_{\mathrm{ex}}=500 \mathrm{~nm}\right.$, grey shading = region of pump scattering) and kinetics at $475 \mathrm{~nm}$ of radical grow in from excited singlet (bottom).

Thus a similar sequence of events, namely singlet state popu lation which then decays to give way to radical pairs (which relax in $3.8 \mathrm{ps)}$ is observed. However, no evidence of triplet population from the short lived radicals is observed in water and the rate of charge separation is around one order of magnitude higher compared to that measured in THF.

The initial non linear effects on the spectrum of $\mathbf{2}$ in Fig. 7 are stronger and superposed with the excited singlet state absorption band. The excited singlet state absorption band of 2 at $425 \mathrm{~nm}$ relaxes in $1.2 \mathrm{ps}$. The same time constant is obtained considering either ground state bleaching or the stimulated emission signal. After fast relaxation, anion radical absorption bands of BODIPY still remain at $425 \mathrm{~nm}$ and between $600800 \mathrm{~nm}$ with a decay time of 21 ps. No triplet formation is observed for these mole cules, which is coherent with the case of $\mathbf{1}$ in water.

On binding $\mathrm{Ca}^{2+}$ the oxidation potential of the receptor changes, rendering electron transfer energetically unfavourable, which blocks radical formation, thereby restoring fluorescence. Indeed, steady state emission is consistent with this process, while time resolved absorption spectra allow direct visualisation of these processes. Transient absorption spectra are similar to those observed in THF for $\mathbf{1 a} \cdot \mathrm{H}^{+}$and $\mathbf{2 a} \cdot \mathrm{H}^{+}$(vide supra), showing that charge separation is not taking place and fluor escence is greatly enhanced.

In the case of $1 . \mathrm{Ca}^{2+}$, the stimulated emission decays with a time constant of $600 \mathrm{ps}$, while that of $2 . \mathrm{Ca}^{2+}$ decays in $760 \mathrm{ps}$. Dividing the fluorescence quantum yields (Table 1) by the apparent lifetime obtained from stimulated emission decays gives an estimation of the radiative rate constant. The values give radiative rate constants of $6.7 \times 10^{7} \mathrm{~s}^{-1}$ and $1.2 \times 10^{8} \mathrm{~s}^{-1}$ for $\mathbf{1}$ and 2, respectively, which is on a typical order of magnitude for BODIPY chromophores (generally around $2 \times 10^{8} \mathrm{~s}^{-1}$ ). ${ }^{38}$ Corres ponding non radiative rate constants are similar at $1.7 \times 10^{9} \mathrm{~s}^{-1}$ and $1.3 \times 10^{9} \mathrm{~s}^{-1}$ for $\mathbf{1}$ and $\mathbf{2}$, respectively.

Concerning the rate of charge separation $\left(k_{\mathrm{ET}}\right)$, this can be estimated according to eqn (2), where $1 / \tau_{\text {free }}$ corresponds to the rate of deexcitation in the absence of ion, while $1 / \tau_{\mathrm{Ca}}{ }^{2+}$ is the rate of deexcitation in the presence of ion, assuming to a first approximation that other rate parameters are not significantly perturbed by the presence of the ion. Both values are based on stimulated emission decays.

$$
k_{\mathrm{ET}}=\frac{1}{\tau_{\text {free }}}-\frac{1}{\tau_{\mathrm{Ca}^{2+}}}
$$

Thus the electron transfer rates for BODIPY BAPTA conjugates $\mathbf{1}$ and $\mathbf{2}$ in water are estimated to be as high as $3.3 \times 10^{12} \mathrm{~s}^{-1}$ and $8.3 \times 10^{11} \mathrm{~s}^{-1}$, respectively.

\section{Conclusions}

Two novel BODIPY BAPTA conjugates which show efficient binding and $\mathrm{Ca}^{2+}$ induced fluorescence enhancements in pseudo physiological media are reported. Fast photoinduced electron transfer from the receptor to the excited BODIPY fluorophore $\left(k_{\mathrm{ET}}=8.3 \times 10^{11} \mathrm{~s}^{-1}\right)$ occurs when the two func tional units are bridged by a phenyl group (2), while this rate is further increased to $k_{\mathrm{ET}}=3.3 \times 10^{12} \mathrm{~s}^{-1}$ when the two units are directly linked in 1. Significant differences between behaviour in polar aprotic THF and water are observed. Indeed, electron trans fer is several times faster in water and, unlike organic solvent, no spectral evidence for triplet formation from the charge separated state was obtained. As a consequence of the ion modulated PET channel, fluorescence enhancements of 122 and 23 are observed for $\mathbf{1}$ and $\mathbf{2}$ in the presence of $\mathrm{Ca}^{2+}$, respectively, making these effective fluorescence chemosensors. While the receptor spacer fluorophore format in $\mathbf{2}$ allows greater predictability of behaviour, as each unit retains its individual characteristics, ulti mately the directly connected conjugate proved a more efficient switch.

\section{Acknowledgements}

This article is dedicated to Jean Pierre Desvergne, a pioneer in the area of photoionic molecular systems. Financial support from the European Research Council under the European Commu nity's Seventh Framework Programme (FP7/2008 2013) ERC grant agreement no. [208702]; Région Aquitaine; Ministère de la Recherche et de l'Enseignement Supérieur (P.B.); CNRS is gratefully acknowledged.

\section{Notes and references}

1 (a) E. L. Que, D. W. Domaille and C. J. Chang, Metals in neuro-biology: probing their chemistry and biology with molecular imaging, Chem. Rev., 2008, 108, 1517 1549; (b) H. N. Kim, M. H. Lee, H. J. Kim, J. S. Kim and J. Yoon, A new trend in rhodamine-based chemosensors: application 
of spirolactam ring-opening to sensing ions, Chem. Soc. Rev., 2008, 37, 14651472.

2 (a) M. J. Berridge, P. Lipp and M. D. N. Bootman, The versatility and universality of calcium signalling, Nat. Rev. Mol. Cell Biol., 2000, 1, 11; (b) M. J. Berridge, M. D. Bootman and H. L. Roderick, Calcium: calcium signaling: dynamics, homeostasis and remodeling, Nat. Rev. Mol. Cell Biol., 2003, 4, 517 529; (c) S. Orrenius, B. Zhivotovsky and P. Nicotera, Calcium: regulation of cell death: the calcium-apoptosis link, Nat. Rev. Mol. Cell Biol., 2003, 4, 552 565; (d) R. Rizzuto and T. Pozzan, Microdomains of intracellular $\mathrm{Ca}^{2+}$ : molecular determinants and functional consequences, Physiol. Rev., 2006, 86, 369408.

3 (a) A. P. de Silva, H. Q. N. Gunaratne, T. Gunnlaugsson, A. J. M. Huxley, C. P. McCoy, J. T. Rademacher and T. E. Rice, Signaling recognition events with fluorescent sensors and switches, Chem. Rev., 1997, 97, 1515 1566; (b) Chemosensors of Ion and Molecule Recognition, ed. J.-P. Desvergne and A. W. Czarnik, Kluwer Academic Press, Dordrecht, 1997.

4 P. A. Otten, R. E. London and L. A. Levy, A new approach to the synthesis of APTRA indicators, Bioconjugate Chem., 2001, 12, 7683.

5 R. Y. Tsien, New calcium indicators and buffers with high selectivity against magnesium and protons: design, synthesis, and properties of prototype structures, Biochemistry, 1980, 19, 23962404.

6 G. Grynkiewicz, M. Poenie and R. Y. Tsien, A new generation of calcium indicators with greatly improved fluorescence properties, J. Biol. Chem., 1985, 260, 33403350.

7 (a) A. V. Agronskaia, L. Tertoolen and H. C. Gerritsen, Fast fluorescence lifetime imaging of calcium in living cells, J. Biomed. Opt., 2004, 9, 1230 1237; (b) L. Schoutteten, P. Denjean, J. Faure and R. B. Pansu, Photophysics of calcium green 1 in vitro and in live cells, Phys. Chem. Chem. Phys., 1999, 1, 2463 2469; (c) J. Ji and Z. Rosenzweig, Fiber optic $\mathrm{pH} / \mathrm{Ca}^{2+}$ fluorescence microsensor based on spectral processing of sensing signals, Anal. Chim. Acta, 1999, 397, 93 102; (d) J. F. Callan, A. P. de Silva, D. B. Fox, N. D. McClenaghan and K. R. A. S. Sandanayake, The anthracen-9-ylmethyloxy unit: an underperforming motif within the fluorescent PET (photoinduced electron transfer) sensing framework, J. Fluoresc., 2005, 15, 769 775; (e) Fluorescent Chemosensors of Ion and Molecule Recognition, ed. A. W. Czarnik, ACS Symp. Ser. 538, American Chemical Society, Washington DC, 1993; $(f)$ A. P. de Silva and H. Q. N. Gunaratne, J. Chem. Soc., Chem. Commun., 1990, 186.

8 H. M. Kim, B. R. Kim, J. H. Hong, J.-S. Park, K. J. Lee and B. R. Cho, A two-photon fluorescent probe for calcium waves in living tissue, Angew. Chem., Int. Ed., 2007, 46, 74457448.

9 A. P. de Silva and N. D. McClenaghan, Proof-of-principle of molecularscale arithmetic, J. Am. Chem. Soc., 2000, 122, 39653966.

10 (a) A. Treibs and F.-H. Kreuzer, Difluoroboryl complexes of di- and tripyrrylmethenes, Justus Liebigs Ann. Chem., 1968, 718, 208 223; (b) G. Ulrich, R. Ziessel and A. Harriman, The chemistry of fluorescent BODIPY dyes: versatility unsurpassed, Angew. Chem., Int. Ed., 2008, 47, 1184 1201; (c) A. Loudet and K. Burgess, BODIPY dyes and their derivatives: syntheses and spectroscopic properties, Chem. Rev., 2007, 107, 4891 4932; (d) R. P. Haugland, The Handbook: A Guide to Fluorescent Probes and Labeling Technologies, Molecular Probes, Invitrogen, Carlsbad, CA, 10th edn, 2005; (e) N. Boens, V. Leen and W. Dehaen, Fluorescent indicators based on BODIPY, Chem. Soc. Rev., 2012, 41, 11301172.

11 M. Baruah, W. Qin, N. Basaric, W. M. De Borggraeve and N. Boens, BODIPY-based hydroxyaryl derivatives as fluorescent $\mathrm{pH}$ probes, J. Org. Chem., 2005, 70, 41524157.

12 (a) C. Goze, G. Ulrich, L. J. Mallon, B. D. Allen, A. Harriman and R. Ziessel, Synthesis and photophysical properties of borondipyrromethene dyes bearing aryl substituents at the boron center, J. Am. Chem. Soc., 2006, 128, 10231 10239; (b) G. Ulrich, C. Goze, M. Guardigli, A. Roda and R. Ziessel, Pyrromethene dialkynyl borane complexes for "cascatelle" energy transfer and protein labeling, Angew. Chem., Int. Ed., 2005, 44, 3694 3698; (c) C. Tahtaoui, C. Thomas, F. Rohmer, P. Klotz, G. Duportail, Y. Mély, D. Bonnet and M. Hibert, Convenient method to access new 4,4-dialkoxy- and 4,4-diaryloxy-diaza-s-indacene dyes: synthesis and spectroscopic evaluation, J. Org. Chem., 2007, 72, 269 272; (d) Y. Gabe, T. Ueno, Y. Urano, H. Kojima and T. Nagano, Tunable design strategy for fluorescence probes based on 4-substituted BODIPY chromophore: improvement of highly sensitive fluorescence probe for nitric oxide, Anal. Bioanal. Chem., 2006, 386, 621 626; (e) T. Rohand, M. Baruah, W. Qin, N. Boens and W. Dehaen, Functionalisation of fluorescent BODIPY dyes by nucleophilic substitution, Chem. Commun., 2006, 266268.
13 A. Palma, M. Tasior, D. O. Frimannsson, T. T. Vu, R. Meallet-Renault and D. F. O'Shea, New on-bead near-infrared fluorophores and fluorescent sensor constructs, Org. Lett., 2009, 11, 36383641.

14 (a) B. K. Kaletas, R. M. Williams, B. König and L. De Cola, Strong fluorescence enhancement of 2-bromo-3-( $1 H$-indol-3-yl)maleimide upon coordination to a Lewis-acidic metal complex, Chem. Commun., 2002, 776 777; (b) B. K. Kaletas, H. C. Joshi, G. van der Zwan, M. Fanti, F. Zerbetto, K. Goubitz, L. De Cola, B. König and R. M. Williams, Asymmetric indolylmaleimide derivatives and their complexation with Zinc(II)-Cyclen, J. Phys. Chem., 2005, 109, 94439455.

15 W. Qin, M. Baruah, W. M. De Borggraeve and N. Boens, Photophysical properties of an on/off fluorescent $\mathrm{pH}$ indicator excitable with visible light based on a boron-dipyrromethene-linked phenol, J. Photochem. Photobiol., A, 2006, 183, 190197.

16 K. Yamada, Y. Nomura, D. Citterio, N. Iwasawa and K. Suzuki, Highly sodium-selective fluoroionophore based on conformational restriction of oligoethyleneglycol-bridged biaryl boron-dipyrromethene, J. Am. Chem. Soc., 2005, 127, 69566957.

17 (a) J.-P. Malval, I. Leray and B. Valeur, A highly selective fluorescent molecular sensor for potassium based on a calix[4]bisazacrown bearing boron-dipyrromethene fluorophores, New J. Chem., 2005, 29, 1089 1094; (b) M. Baruah, W. Qin, R. A. L. Vallée, D. Beljonne, T. Rohand, W. Dehaen and N. Boens, A highly potassium-selective ratiometric fluorescent indicator based on BODIPY azacrown ether excitable with visible light, Org. Lett., 2005, 7, 43774380.

18 N. Basaric, M. Baruah, W. Qin, B. Metten, M. Smet, W. Dehaen and N. Boens, Synthesis and spectroscopic characterisation of BODIPY based fluorescent off-on indicators with low affinity for calcium, Org. Biomol. Chem., 2005, 3, 27552761.

19 A. Coskun and E. U. Akkaya, Ion sensing coupled to resonance energy transfer: a highly selective and sensitive ratiometric fluorescent chemosensor for Ag(I) by a modular approach, J. Am. Chem. Soc., 2005, 127, 1046410465.

20 Y. Wu, X. Peng, B. Guo, J. Fan, Z. Zhang, J. Wang, A. Cui and Y. Gao, Boron dipyrromethene fluorophore based fluorescence sensor for the selective imaging of Zn(II) in living cells, Org. Biomol. Chem., 2005, 3, 13871392

21 O. A. Bozdemir, R. Guliyev, O. Buyukcakir, S. Selcuk, S. Kolemen, G. Gulseren, T. Nalbantoglu, H. Boyaci and E. U. Akkaya, Selective manipulation of ICT and PET processes in styryl-BODIPY derivatives: applications in molecular magic and fluorescence sensing of metal ions, J. Am. Chem. Soc., 2010, 132, 80298036.

22 K. R. Gee, A. Rukavishnikov and A. Rothe, New $\mathrm{Ca}^{2+}$ fluoroionophores based on the BODIPY fluorophore, Comb. Chem. High Throughput Screening, 2003, 6, 363 366; M. Kamiya and K. Johnsson, Localizable and highly sensitive calcium indicator based on a BODIPY fluorophore, Anal. Chem., 2010, 82, 64726479.

23 T. N. Singh-Rachford, A. Haefele, R. Ziessel and F. N. Castellano, Boron dipyrromethene chromophores: next generation triplet acceptors/annihilators for low power upconversion schemes, J. Am. Chem. Soc., 2008, 130, 1616416165.

24 B. Metten, M. Smet, N. Boens and W. Dehaen, Synthesis of APTRA derivatives as building blocks for low-affinity fluorescent $\mathrm{Ca}^{2+}$ indicators, Synthesis, 2005, 18381844

25 (a) C. Tahtaoui, C. Thomas, F. Rohmer, P. Klotz, G. Duportail, Y. Mély, D. Bonnet and M. Hibert, Convenient method to access new 4,4-dialkoxy- and 4,4-diaryloxy-diaza-s-indacene dyes: synthesis and spectroscopic evaluation, J. Org. Chem., 2007, 72, 269 272; (b) J. Godoy, G. Vives and J. M. Tour, Synthesis of highly fluorescent BODIPY-based nanocars, Org. Lett., 2010, 12, 14641467.

26 J. A. Thomas, P. C. Kolbeck and T. A. Langworthy, in Intracellullar $p H$; Its Measurement, Regulation and Utilization in Cellular Functions, ed. R. Nuccitelli and D. W. Deamer, Liss, New York, 1982, p. 105.

27 J. A. Thomas, in Optical Methods in Cell Physiology, ed. P. de Weer and B. M. Salzberg, Wiley, New York, 1986, p. 311.

28 B. Rotman and B. W. Papermaster, Membrane properties of living mammalian cells as studied by enzymic hydrolysis of fluorogenic esters, Proc. Natl. Acad. Sci. U. S. A., 1966, 55, 134141.

29 H. L. Kee, C. Kirmaier, L. Yu, P. Thamyongkit, W. J. Youngblood, M. E. Calder, L. Ramos, B. C. Noll, D. F. Bocian, W. R. Scheidt, R. R. Birge, J. S. Lindsey and D. Holten, Structural control of the photodynamics of boron dipyrrin complexes, J. Phys. Chem. B, 2005, 109, 2043320443.

30 (a) D.-C. Wang, C. He, J.-L. Fan, W.-W. Huang and X.-J. Peng, Acto Crystallogr., Sect. E: Struct. Rep. Online, 2007, 63, o2900; (b) Y.-H. Yu, 
Z. Shen, H.-Y. Xu, Y.-W. Wang, T. Okujima, N. Ono, Y.-Z. Li and X.-Z. You, Synthesis, crystal structures and spectroscopic characterizations of two difluoroboradiaza-s-indacene dyes, J. Mol. Struct., 2007, 827, 130 136; (c) G. Vives, C. Giansante, R. Bofinger, G. Raffy, A. Del Guerzo, B. Kauffmann, P. Batat, G. Jonusauskas and N. D. McClenaghan, Facile functionalization of a fully fluorescent perfluorophenyl BODIPY: photostable thiol and amine conjugates, Chem. Commun., 2011, 47, 1042510427.

31 X. Yin, Y. Li, Y. Zhu, X. Jing, Y. Li and D. Zhu, A highly sensitive viscosity probe based on ferrocene-BODIPY dyads, Dalton Trans., 2010, 39, 99299935.

32 J. O. Huh, Y. Do and M. H. Lee, Reactivity of bis(silyl)platinum(II) complexes toward organic isothiocyanates: preparation and structures of (dithiocarbonimidato)- and (diphenylsilane-dithiolato) platinum(II)complexes, cis- $\left[\mathrm{Pt}\left(\mathrm{S}_{2} \mathrm{C}: \mathrm{NPh}\right) \mathrm{L}_{2}\right]$ and cis- $\left[\mathrm{Pt}\left(\mathrm{S}_{2} \mathrm{SiPh}_{2}\right) \mathrm{L}_{2}\right]\left(\mathrm{L} \quad \mathrm{PMe}_{2} \mathrm{Ph}, \mathrm{PEt}_{3}\right.$; L L dppp), Organometallics, 2008, 27, 10221025.

33 (a) C.-W. Wan, A. Burghart, J. Chen, F. Bergström, L. B.-A. Johanson, M. F. Wolford, T. G. Kim, M. R. Topp, R. M. Hochstrasser and K. Burgess, Anthracene-BODIPY cassettes: syntheses and energy transfer, Chem. Eur. J., 2003, 9, 4430 4441; (b) Z. Shen, H. Röhr, K. Rurack, H. Uno, M. Spieles, B. Schulz, G. Reck and N. Ono, Borondiindomethene (BDI) dyes and their tetrahydrobicyclo precursors en route to a new class of highly emissive fluorophores for the red spectral range, Chem. Eur. J., 2004, 10, 48534871.

34 MOPAC2009, J. J. P. Stewart, Stewart Computational Chemistry, Version 9.024W web: http://OpenMOPAC.net; General Reference for PM6: "Optimization of Parameters for Semiempirical Methods V: Modification of NDDO Approximations and Application to 70 Elements", J. J. P. Stewart, J. Mol. Model., 2007, 13, 11731213.

35 (a) M. Kollmannsberger, K. Rurack, U. Resch-Genger and J. Daub, Ultrafast charge transfer in amino-substituted boron dipyrromethene dyes and its inhibition by cation complexation: a new design concept for highly sensitive fluorescent probes, J. Phys. Chem. A, 1998, 102, 10211 10220; (b) R. R. Hu, E. Lager, A. Aguilar-Aguilar, J. Liu, J. W. Y. Lam, H. H. Y. Sung, I. D. Williams, Y. Zhong, K. S. Wong, E. Pena-Cabrera and B. Z. Tang, Twisted intramolecular charge transfer and aggregationinduced emission of BODIPY derivatives, J. Phys. Chem. C, 2009, 113, 1584515853.

36 (a) M. Galletta, S. Campagna, M. Quesada, G. Ulrich and R. Ziessel, The elusive phosphorescence of pyrromethene- $\mathrm{BF}_{2}$ dyes revealed in new multicomponent species containing Ru(II)-terpyridine subunits, Chem. Commun., 2005, 4222 4225; (b) M. Galletta, F. Puntoriero, S. Campagna, C. Chiorboli, M. Quesada, S. Goeb and R. Ziessel, Absorption spectra, photophysical properties, and redox behavior of ruthenium(II) polypyridine complexes containing accessory dipyrromethene-BF 2 chromophores, J. Phys. Chem. A, 2006, 110, 43484358.

37 V. J. Richards, A. L. Gower, J. E. H. B. Smith, E. S. Davies, D. Lahaye, A. G. Slater, W. Lewis, A. J. Blake, N. R. Champness and D. L. Kays, Synthesis and characterisation of BODIPY radical anions, Chem. Commun., 2012, 48, 17511753.

38 J. Karolin, L. B.-Å. Johansson, L. Strandberg and T. Ny, Fluorescence and absorption spectroscopic properties of dipyrrometheneboron difluoride (BODIPY) derivatives in liquids, lipid Membranes, and Proteins, J. Am. Chem. Soc., 1994, 116, 78017806. 